\title{
Temperature Field Simulation and Experimental Study of Anti-backlash Single-Roller Enveloping Hourglass Worm Gear
}

\author{
Shisong Wang ${ }^{1}$, Shike Wang ${ }^{1}$, Jie Wang ${ }^{1}$ and Xingqiao Deng ${ }^{2^{*}(1)}$
}

\begin{abstract}
In gear transmission, temperature rise has a non-negligible impact on the accuracy, noise and transmission efficiency. However, there is no relevant research on the temperature rise of the anti-backlash single-roller enveloping hourglass worm (ASEHW) gear. To solve this problem, based on tribology principle and Hertz contact theory, the thermal power calculation method of the ASEHW gear was proposed for the first time and thermal analysis was carried out by Ansys software. The bulk temperature of the ASEHW gear under four different rotating speed (300 r/min, $600 \mathrm{r} / \mathrm{min}, 900 \mathrm{r} /$ $\mathrm{min}, 1200 \mathrm{r} / \mathrm{min}$ ) is calculated. The main factors causing temperature rise of the ASEHW gear are analyzed theoretically. Meanwhile, an experimental study is performed to verify the simulation results and validate the theory methods. The theory presented in this paper provides a solution for the thermal power calculation of ASEHW gear. This research provides a theoretical basis for further optimization of ASEHW gear.
\end{abstract}

Keywords: Roller enveloping hourglass worm gear, Finite element analysis, Temperature field

\section{Introduction}

During the transmission of the gear, due to the relative sliding of the meshing tooth surface, an instantaneous high temperature is generated. The high temperature of this moment is called the flash temperature [1-4]. Since the teeth are constantly engaged at the meshing area, the overall temperature of the gear is increased. The overall temperature of the gear is called the bulk temperature [5-7]. The flash temperatures can cause teeth bonding, resulting in dynamic loads, noise, and increased tooth wear [8]. If the bulk temperature is too high, the thermal expansion of the gear will cause the meshing gap between the gears to become smaller, which will lead to increased power loss [9]. Since the gear temperature rise has a huge impact on the life of the reducer, the temperature rise in

\footnotetext{
*Correspondence: dengxingqiao19@cdut.edu.cn

${ }^{2}$ College of Nuclear Technology and Automation Engineering, Chengdu University of Technology, Chengdu 610059, China

Full list of author information is available at the end of the article
}

the gear transmission process has always been a hot and difficult point for experts at home and abroad.

Generally, the research methods of gear temperature rise include experimental method, simulation analysis method, experimental method and simulation analysis. Using experimental method, Mao et al. $[10,11]$ tested the relationship between temperature and tooth wear of a kind of polymer composite gear. Yi et al. [12] use of thermocouples to check the gear surface temperature. The above experimental method can effectively measure the gear surface temperature, but the experimental method has strict requirements on the conditions, the gear surface temperature can only be accurately measured at a relatively constant ambient temperature.

With the gradual improvement of numerical analysis methods, simulation analysis has become a high-efficiency and low-cost research method. Using simulation analysis methods, Shi et al. [13] obtained the steady temperature field and tooth surface flash temperature of the gear through simulation analysis. Fernandes et al. [14] used the finite element method to construct a gear 
finite model of the bulk temperature and flash temperature. Luo et al. [15] used APDL to establish a single-tooth finite element model, analyzed the factors affecting the bulk temperature. Cerne et al. [16] established a prediction model of gear flash temperature by using finite element model. The simulation analysis method can effectively analyze the gear temperature, but it also has high requirements for the accuracy of input parameters.

Therefore, the simulation analysis method is firstly used for analysis, and then the experimental method is used to verify the results in the simulation analysis method. After verifying the accuracy of the results, the simulation analysis method can be used to provide theoretical guidance for future research. Using this method, Li et al. $[17,18]$ calculated the temperature field of the gear, and carried out experimental comparison to verify the effectiveness of the simulation analysis. Koffe et al. [19] proposed a numerical model of friction power loss in gear transmission, and verified the accuracy of the model through experiments. Long et al. [20] studied the influence of relevant parameters on the surface temperature of high-speed gear, and verified the effectiveness of simulation analysis through experimental comparison. Chang et al. [21] simulated the tooth surface temperature of spur gear with the consideration of the change of gear motion heat source and the correctness of the simulation results is compared by experiments.

To sum up, the temperature rise experiment is a very important link in the study of gear temperature rise. Firstly, the corresponding results are obtained by simulation and the correctness of the results is verified by experiments. The correct simulation model can be directly used for analysis and research, so that the cost of research can be reduced accordingly.

Compared with the traditional gear, the anti-backlash single-roller enveloping hourglass worm (ASEHW) gear converts the sliding friction into rolling friction due to the special structure of the roller on the worm wheel. This greatly improves the transmission efficiency. For this kind of worm wheel and worm, it was studied in transmission theory [22], machining optimization [23] and lubrication analysis [24]. But the temperature field of the ASEHW gear has not been studied. One of the reasons is that because of the special structure of the worm wheel, the anti-backlash roller enveloping hourglass worm gear can not refer to the temperature field calculation method of the traditional gear drive. However, the temperature rise has a great influence on the performance of the ASEHW gear, and the study of temperature rise can provide theoretical basis for further parameter optimization. So how to correctly calculate the temperature field of the anti-backlash roller enveloping hourglass worm gear is very necessary.
Based on the above situation, this paper uses the combination of experimental method and simulation analysis to study the temperature field of the ASEHW gear. The structure of this paper is as follows: in the first part, the calculation method of thermal power and convection heat transfer coefficient of the ASEHW gear is constructed, the second part is the temperature rise simulation of the ASEHW gear, the third part is the temperature rise experiment and the comparison with the simulation results. the last part is conclusion.

\section{Calculation of Thermal Power and Convective Heat Transfer Coefficient}

In calculating the temperature field of the ASEHW gear, it is necessary to calculate the thermal power and convection heat transfer coefficient in the transmission process.

\subsection{Calculation of Thermal Power}

When the ASEHW gear is working, since the tooth surface is rolling friction, it cannot be calculated with reference to the general gear. Here we divide the thermal power of the ASEHW gear into two parts, the first part is the power loss caused by rolling friction between roller and worm surface, the second part is the power loss caused by rolling friction between the inner roller and the inner and outer ring.

\subsubsection{Calculation of Thermal Power on Roller Outer Ring Rolling Friction}

According to the research in Ref. [25], the rolling of the roller on the worm can be simplified to the rolling of the cylinder on the surface, the main energy loss of the rolling friction $Q_{e}$ is composed of two parts: one part is the energy loss of elastic hysteresis $Q_{\delta}$ and the other part is the energy loss of adhesive effect $Q_{\alpha}$. As shown in Eq. (1):

$$
\left\{\begin{array}{l}
Q_{e}=Q_{\delta}+Q_{\alpha}, \\
Q_{\delta}=\frac{2 \alpha P a}{3 \pi} \times \frac{x}{R}, \\
Q_{\alpha}=\frac{2 \sigma_{b}+\sigma_{s}}{12 H_{B}} \times \frac{a P x}{R},
\end{array}\right.
$$

where $\alpha$ is the elastic hysteresis coefficient, $P$ is the contact surface positive pressure, $a$ is the contact half width, $R$ is the cylinder radius, $x$ is the distance that the roller rolls on the worm, $\sigma_{b}$ is the tensile strength of the softer materials in the two materials, $\sigma_{s}$ is the yield strength of the softer materials in the two materials, $H_{B}$ is the Brinell Hardness of the harder materials in the two materials.

The contact half width can be determined by the Hertz contact theory [26]: 


$$
a=\left[\frac{4 P R}{\pi l}\left(\frac{1-\mu_{1}^{2}}{E_{1}}+\frac{1-\mu_{2}^{2}}{E_{2}}\right)\right]^{1 / 2},
$$

where $l$ is the length of the contact line, $E_{1}$ and $E_{2}$ are the elastic modulus of the roller and worm material, $\mu_{1}$ and $\mu_{2}$ are the Poisson's ratio of the roller and worm material.

The roller is in the process of rolling, $P$ varies with $x$, that is, $P=P(x)$, and substitute it into Eqs. (1), (2):

$$
\left\{\begin{array}{l}
\Delta Q_{\delta}=\frac{2 \alpha P(x) a}{3 \pi R} \mathrm{~d} x, \\
\Delta Q_{\alpha}=\frac{\left(2 \sigma_{b}+\sigma_{s}\right) a P(x)}{12 H_{B} R} \mathrm{~d} x, \\
a=\left[\frac{4 P(x) R}{\pi l}\left(\frac{1-\mu_{1}^{2}}{E_{1}}+\frac{1-\mu_{2}^{2}}{E_{2}}\right)\right]^{1 / 2} .
\end{array}\right.
$$

By arranging Eqs. (1)-(3), we can obtain the energy loss caused by the rolling friction between roller and worm surface in the meshing process:
When the roller rotates the angle of $\mathrm{d} \theta$, the energy lost $Q_{i}$ can be calculated:

$$
\Delta Q_{i}=M_{f} \mathrm{~d} \theta .
$$

There is also a relationship between the rolling distance and the angle of rotation:

$$
\mathrm{d} x=R \mathrm{~d} \theta .
$$

Because $n$ varies with $x$, that is, $n=n(x)$. By arranging Eqs. (6)-(8), we can obtain $Q_{i}$ caused by the roller rotation in the meshing process:

$$
Q_{i}=\int_{0}^{x} \frac{\mu d_{m} P(x)+f_{o}\left[v_{o} n(x)\right]^{2 / 3} d_{m}^{3} \times 10^{-7}}{R} \mathrm{~d} x .
$$

Therefore, when the worm wheel is rotated once, the average loss of power per inside each roller $H_{i}$ is obtained:

$$
H_{i}=\frac{Q_{i}}{t}
$$

$$
Q_{\mathrm{e}}=\int_{0}^{x}\left(\frac{2 \alpha}{3 \pi R}+\frac{2 \sigma_{b}+\sigma_{s}}{12 H_{B} R}\right)\left[\frac{4 R}{\pi l}\left(\frac{1-\mu_{1}^{2}}{E_{1}}+\frac{1-\mu_{2}^{2}}{E_{2}}\right)\right]^{1 / 2} P(x)^{3 / 2} \mathrm{~d} x .
$$

Therefore, when the worm wheel is rotated once, the average loss of power per roller outer ring $H_{\mathrm{e}}$ is obtained:

$$
H_{e}=\frac{Q_{e}}{t},
$$

where $t$ is the time taken for the worm wheel to rotate one week.

\subsubsection{Calculation of Thermal Power inside the Roller}

Each roller on the worm wheel is composed of an outer ring, an inner ring, a rolling body and a cage. Therefore, the thermal power inside the roller can refer to the calculation method of bearing thermal power. It is known from Ref. [27] that the total friction torque of the roller $M_{f}$ mainly consists of two parts, one part is the frictional moment caused by the load $M_{l}$, the other part is the viscous resistance moment caused by the viscosity of lubricating oil inside the roller $M_{v}$ :

$$
\left\{\begin{array}{r}
M_{f}=M_{l}+M_{v}, \\
M_{l}=\mu P d_{m} \\
M_{v}=f_{o}\left(v_{\mathrm{o}} n\right)^{2 / 3} d_{m}^{3} \times 10^{-7},
\end{array}\right.
$$

where $\mu$ is the friction coefficient of the roller, $d_{m}$ is the pitch diameter of the roller, $f_{o}$ is the coefficient related to the bearing type and lubrication method, $n$ is the rotational speed of the outer ring of the roller, $v_{o}$ is the kinematic viscosity of the lubricating oil.

\subsection{Calculation of Convective Heat Transfer Coefficient}

The convective heat transfer coefficient of the ASEHW gear can refer to the calculation method of traditional gear drive. In Ref. [15], the convective heat transfer coefficient of gear is calculated in detail. The convective heat transfer coefficient of the ASEHW gear is divided into two parts: the top and side of the worm and worm wheel, meshing surface.

\subsubsection{Convective Heat Transfer Coefficient of the Top and Side of Worm and Worm Wheel}

The convective heat transfer between the top surface and the side surface of the ASEHW gear and the lubricating oil can be simplified as the convective heat transfer of the lubricating oil through the thin plate. The convective heat transfer coefficient $h_{d}$ is as follows:

$$
h_{d}=\lambda_{o} \frac{N u}{r_{a}}=0.664 \lambda_{o} P_{o}^{0.333}\left(\frac{\omega}{v_{o}}\right)^{0.5},
$$

where $N u$ is the Nusselt number of the lubricating oil, $P_{o}$ is the Prandtl number of the lubricating oil, $\omega$ is the rotational speed of the worm wheel and the worm, $\lambda_{o}$ is the thermal conductivity of the lubricating oil.

$P_{o}$ can be obtained by the following formula:

$$
P_{o}=\frac{\rho_{o} c_{o} v_{\mathrm{o}}}{\lambda_{o}},
$$


where $\rho_{o}$ is the density of the lubricating oil, $c_{o}$ is the specific heat capacity of the lubricating oil.

\subsubsection{Convective Heat Transfer Coefficient of the Meshing Surface}

The convection heat transfer coefficient of meshing surface $h_{m}$ is as follows:

$$
h_{m}=0.228 R e^{0.731} P^{0.333} \frac{\lambda_{o}}{L_{d}},
$$

where $L_{d}$ is the pitch circle diameter, $R e$ is the Reynolds number.

$R e$ can be obtained by the following formula:

$$
R e=\frac{\omega \cdot r_{c}^{2}}{v_{o}}
$$

where $r_{c}$ is the radius of the worm wheel and worm meshing point.

\subsubsection{Thermal Power Distribution Coefficient of the Meshing Surface}

Since $H_{e}$ is generated by roller rolling on the surface of worm tooth, $H_{e}$ is jointly distributed by worm tooth surface and roller surface. Distribution coefficients $k_{1}$ and $k_{2}$ are shown as follows:

$$
\begin{aligned}
& k_{1}=\frac{\sqrt{\lambda_{1} \rho_{1} c_{1} u_{1}}}{\sqrt{\lambda_{1} \rho_{1} c_{1} u_{1}}+\sqrt{\lambda_{2} \rho_{2} c_{2} u_{2}}}, \\
& k_{2}=\frac{\sqrt{\lambda_{2} \rho_{2} c_{2} u_{2}}}{\sqrt{\lambda_{1} \rho_{1} c_{1} u_{1}}+\sqrt{\lambda_{2} \rho_{2} c_{2} u_{2}}},
\end{aligned}
$$

where $\lambda_{1}, \rho_{1}, c_{1}, u_{1}$ and $\lambda_{2}, \rho_{2}, c_{2}, u_{2}$ are the thermal conductivity, density, specific heat capacity and poisson's ratio of worm gear and roller materials, respectively

\section{Simulation Analysis}

In the second chapter, the calculation method of thermal power and convective heat transfer coefficient of the ASEHW gear is constructed. For the subsequent analysis, the relevant parameters are listed in the table, as shown in Tables 1, 2, 3. And based on the relevant parameters to build an accurate 3D model, methods of model construction Refs. [28-30], the model shown in Figure 1.

Table 1 Design parameters

\begin{tabular}{llll}
\hline $\begin{array}{l}\text { Center distance } \\
\boldsymbol{A}(\mathbf{m m})\end{array}$ & $\begin{array}{l}\text { Transmission ratio } \\
\boldsymbol{i}_{\mathbf{1 2}}\end{array}$ & $\begin{array}{l}\text { Roller radius } \\
\boldsymbol{R}(\mathbf{m m})\end{array}$ & $\begin{array}{l}\text { Modulus } \\
\boldsymbol{M}(\mathbf{m m})\end{array}$ \\
\hline 80 & 30 & 5 & 4.4 \\
\hline
\end{tabular}

Table 2 Lubricating oil parameters

\begin{tabular}{llll}
\hline $\begin{array}{l}\text { Density } \\
\boldsymbol{\rho}_{\boldsymbol{o}}\left(\mathrm{kg} / \mathrm{m}^{\mathbf{3}}\right)\end{array}$ & $\begin{array}{l}\text { Kinematic } \\
\text { viscosity } \\
\boldsymbol{v}_{\boldsymbol{o}}(\mathrm{cst})\end{array}$ & $\begin{array}{l}\text { Specific heat } \\
\text { capacity } \\
\boldsymbol{c}_{\boldsymbol{o}}(\mathrm{J} /(\mathbf{k g} \cdot \mathrm{K}))\end{array}$ & $\begin{array}{l}\text { Thermal } \\
\text { conductivity } \\
\lambda_{\boldsymbol{o}}(\mathrm{W} /(\mathrm{m} \cdot \mathrm{K}))\end{array}$ \\
\hline 873 & 101.8 & 1880 & 0.15 \\
\hline
\end{tabular}

\subsection{Calculation of the Positive Pressure on the Contact} Surface

In the process of meshing, the positive pressure of contact surface between roller and worm will change with the change of meshing position. Because it is difficult to solve the load distributing between teeth by analytic method, the transient dynamics module of Ansys is used to solve the load distributing between teeth. In addition, it takes a lot of calculation time to solve a complete meshing process, So the calculation process is simplified, the change of the force on the roller during a meshing period is equivalent to the force on five rollers at the same time. Cording to the previously constructed 3D model, considering the efficiency and accuracy of the finite element analysis, the model is simplified to some extent: the keyway, chamfer and other features are removed, and only the five rollers that are simultaneously meshed are considered. Then, it is imported into Ansys for mesh division. The focus is on the mesh refinement of the roller and the worm tooth surface. The result of meshing is shown in Figure 2. The model has 382700 nodes and 254174 grids.

When the load torque of worm wheel $T=50 \mathrm{~N} \cdot \mathrm{m}$, the distribution of load between teeth is obtained. And for the convenience of subsequent analysis, a coordinate system as shown in Figure 3 is established on each roller, the $z$-axis is on the rotation axis of the roller, the $x$-axis is parallel to the worm wheel axis, and the $y$-axis is perpendicular to the $x$ - and $z$-axes.

The load shared by each roller is obtained through simulation calculation. The component force in each direction is obtained by post-processing and fits into a curve. This curve can be equivalent to the force change of the roller in one meshing period. As shown in Figure 4.

It can be seen from Figure 4 that the normal force $F_{y}$ is the largest, followed by the tangential force $F_{x}$ and the axial force $F_{z}$ is the smallest in the whole engagement period. In addition, the values of $F_{x}$ and $F_{z}$ do not change very much in the whole meshing process. $F_{y}$ increases gradually between the roller enter worm and the roller reaches the throat. When it reaches the throat, $F_{y}$ reaches its maximum value, while the roller leaves the worm from the throat, $F_{y}$ decreases gradually. $F_{y}$ is positive pressure $P$. 
Table 3 worm and roller material parameters

\begin{tabular}{lllllllll}
\hline & $\begin{array}{l}\text { Elastic } \\
\text { modulus } \\
\boldsymbol{E}(\mathrm{GPa})\end{array}$ & $\begin{array}{l}\text { Poisson's ratio } \\
\boldsymbol{\mu}\end{array}$ & $\begin{array}{l}\text { Tensile } \\
\text { strength } \\
\boldsymbol{\sigma}_{\boldsymbol{b}}(\mathbf{M P a})\end{array}$ & $\begin{array}{l}\text { Brinell } \\
\text { hardness } \\
\boldsymbol{H}_{\boldsymbol{B}}\left(\mathbf{N} / \mathbf{m m}^{2}\right)\end{array}$ & $\begin{array}{l}\text { Density } \\
\boldsymbol{\rho}\left(\mathbf{k g} / \mathbf{m}^{\mathbf{3}}\right)\end{array}$ & $\begin{array}{l}\text { Specific heat } \\
\text { capacity } \\
\boldsymbol{c}(\mathbf{J} /(\mathbf{k g} \cdot \mathbf{K}))\end{array}$ & $\begin{array}{l}\text { Thermal } \\
\text { conductivity } \\
\boldsymbol{\lambda}(\mathbf{W} /(\mathbf{m} \cdot \mathbf{K}))\end{array}$ & $\begin{array}{l}\text { Yield strength } \\
\boldsymbol{\sigma}_{\boldsymbol{s}}(\mathbf{M P a})\end{array}$ \\
\hline Worm & 210 & 0.3 & 600 & 197 & 7850 & 465 & 46 & 355 \\
Roller & 210 & 0.3 & 860 & 618 & 7850 & 465 & 46 & 518 \\
\hline
\end{tabular}

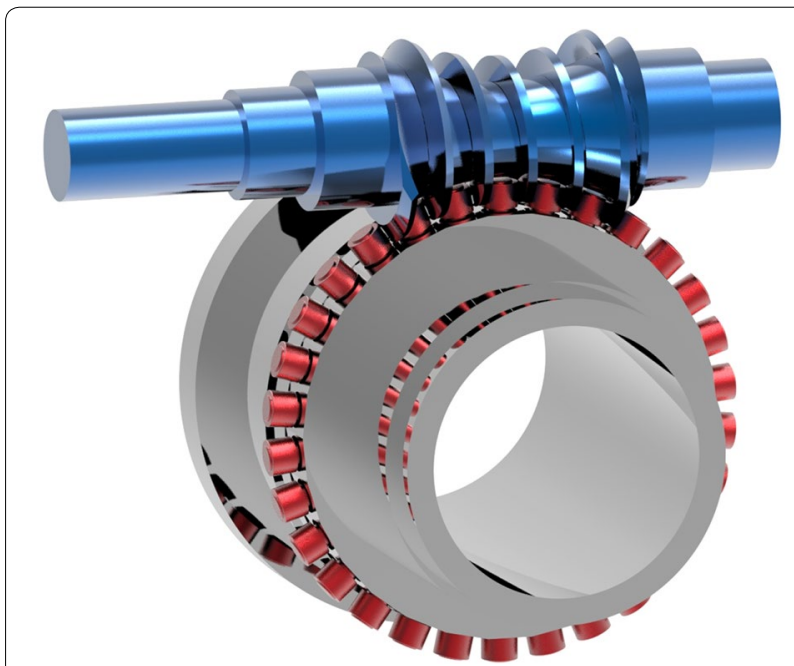

Figure 1 ASEHW gear model

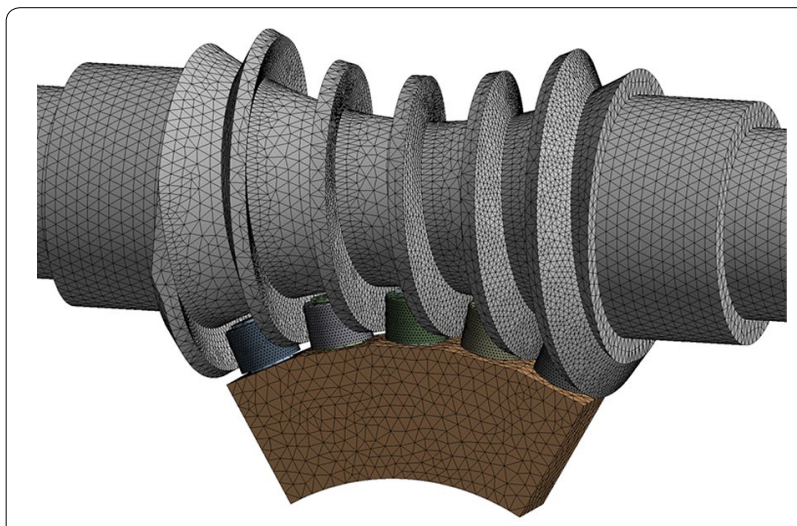

$\mathbf{a}$

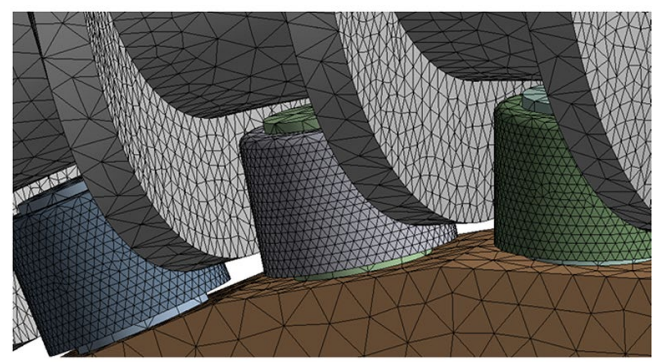

b

Figure 2 a Global meshing, b refinement meshing

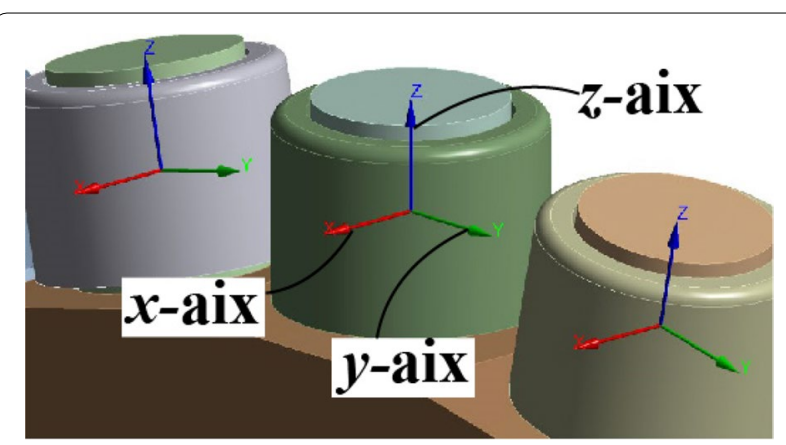

Figure 3 Coordinate system establishment

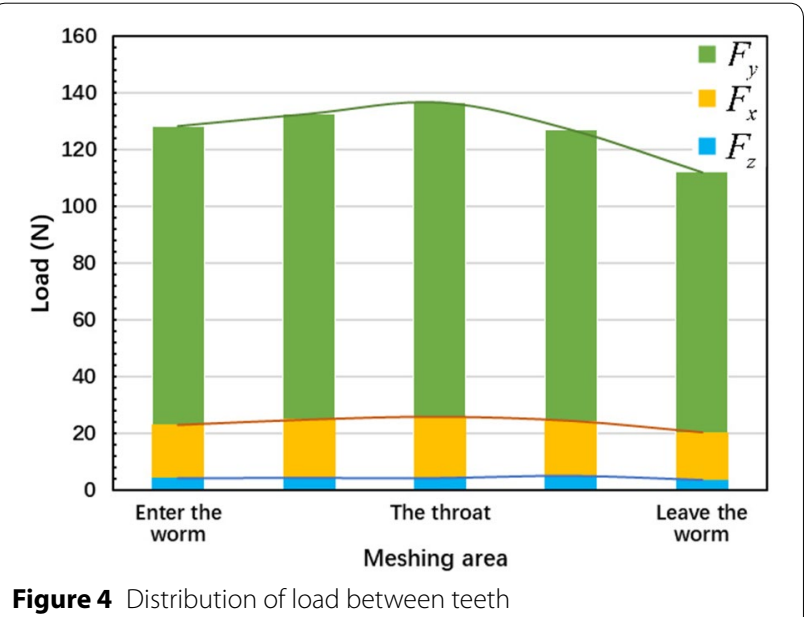

\subsection{Calculation of Roller Speed}

During the process when the roller enters the worm, the rotation speed of the roller will suddenly change. Compared with the whole meshing period, this sudden change process is very short, so it is not considered in the calculation of temperature rise. During the rotation of the worm gear, the roller and the meshed worm surface are theoretically purely rolling. However, due to the error of machining and manufacturing, as well as the impact and vibration of meshing, the roller may be stuck or slip. Because the influencing factors are too complicated, here the roller and worm surface are calculated as pure rolling, so the roller speed is shown as follows: 


$$
n=\frac{v}{2 \pi R}
$$

where $v$ is the tangential velocity of the worm at the point of contact.

The rotation speed of the roller during the entire engagement period is shown in Figure 5. It can be seen that the speed of the roller is maximum when entering and leaving the worm and the minimum in throat position. With the increase of worm speed, the roller speed difference between entering and leaving worm and throat is more obvious.

\subsection{Simulation Analysis of Temperature Field}

In the previous chapter, positive pressure and roller speed curves were solved, so the thermal power and convective heat transfer coefficient could be solved, as shown in Figure 6 and Figure 7.

It can be seen from Figure 6 that there is a small difference between $H_{i}$ and $H_{e}$ at a low speed, but with the increase of worm speed, $H_{i}$ is significantly higher than $H_{e}$. As can be seen from Figure 7, the convective heat transfer coefficient of worm is much higher than that of worm wheel. Therefore, in the transmission process, the heat dissipation effect of worm wheel is better than that of worm wheel. In addition, both the worm and the worm wheel, $h_{m}$ is greater than $h_{d}$.

The steady-state thermal analysis model was established by using the thermodynamic analysis module of Ansys, as shown in Figure 8. The model has 1625848 nodes and 1124184 grids. The thermal power and the convection heat transfer coefficient were added to the corresponding position. $H_{e}$ is added to the surface of worm tooth and roller respectively according to the distribution coefficient and $H_{i}$ is added to the inner pitch circular surface of each roller.

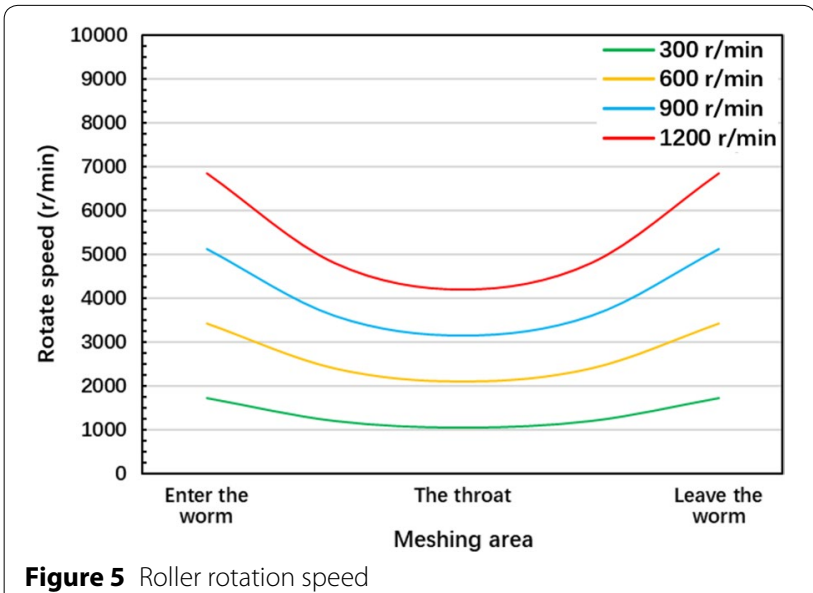

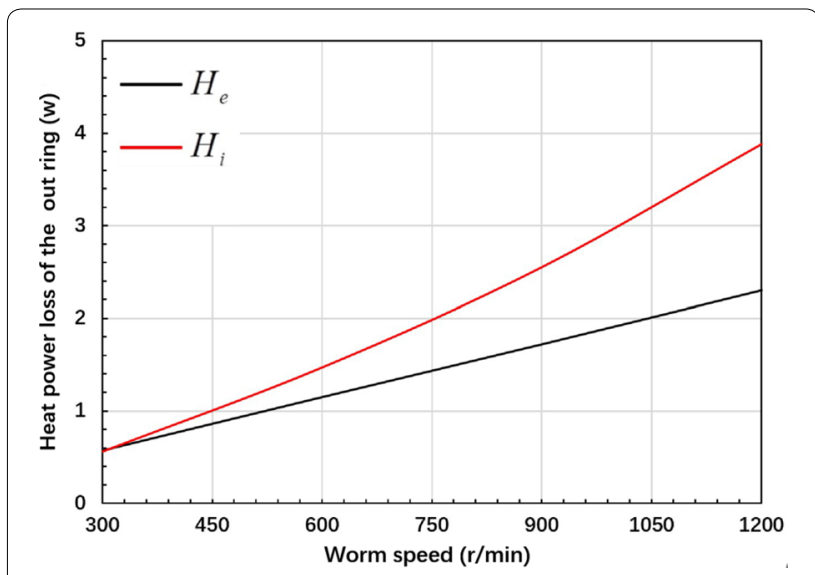

Figure 6 Thermal power loss at different speeds

Through simulation calculation, the temperature distributions of worm and worm wheel at $300 \mathrm{r} / \mathrm{min}, 600$ r/min, $900 \mathrm{r} / \mathrm{min}$, and $1200 \mathrm{r} / \mathrm{min}$ were obtained. For the convenience of comparison, we unified the color

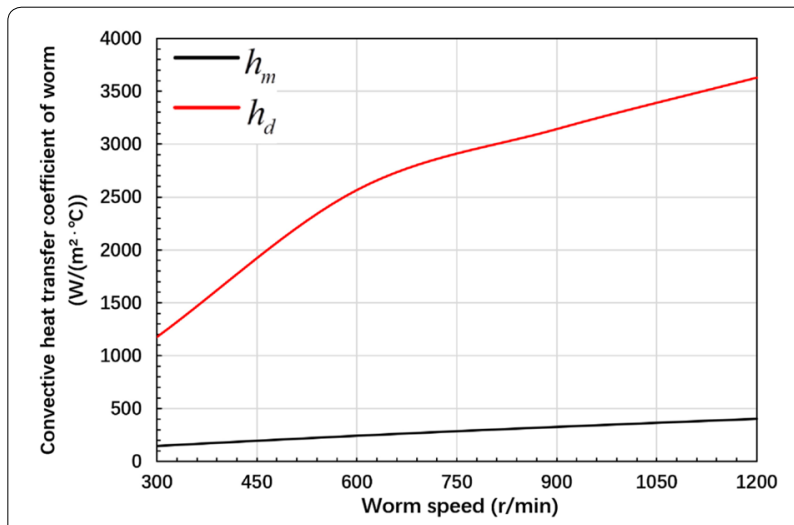

$\mathbf{a}$

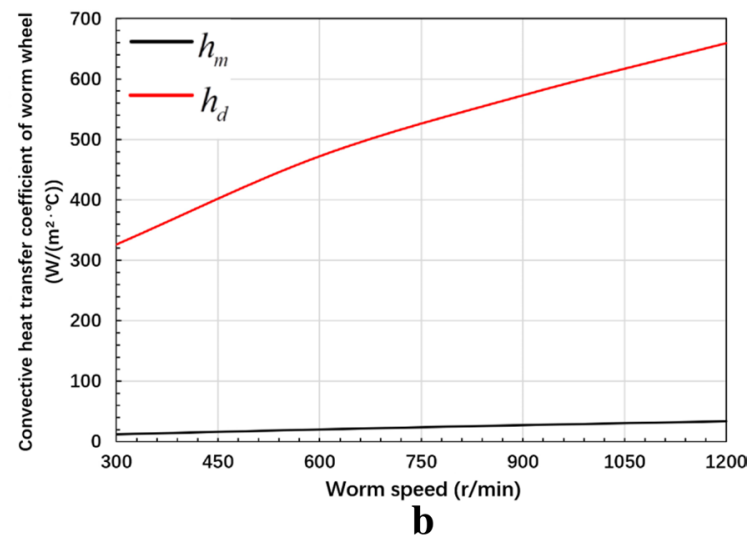

Figure $\mathbf{7}$ a Convection heat transfer coefficient of the worm, $\mathbf{b}$ convective heat transfer coefficient of the worm wheel 


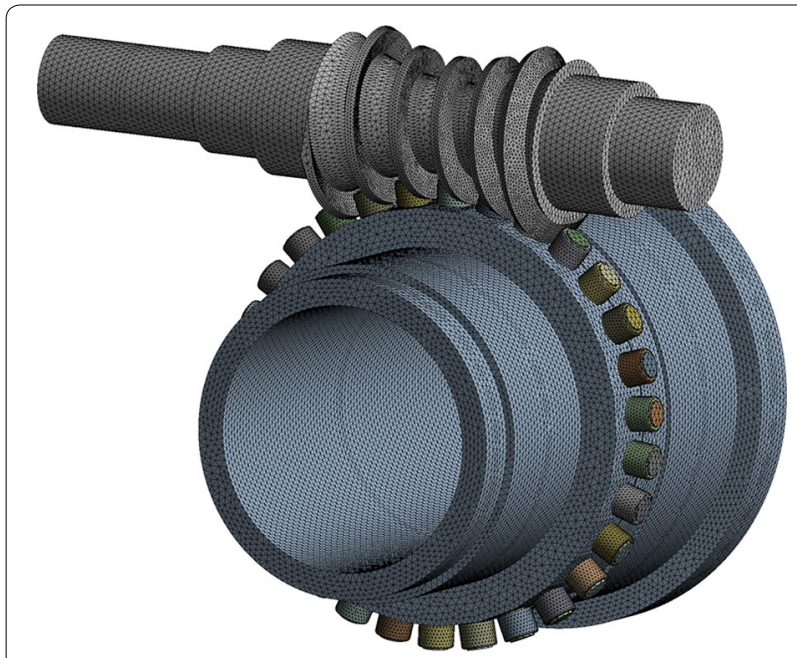

Figure 8 Meshing of the steady-state thermal analysis model

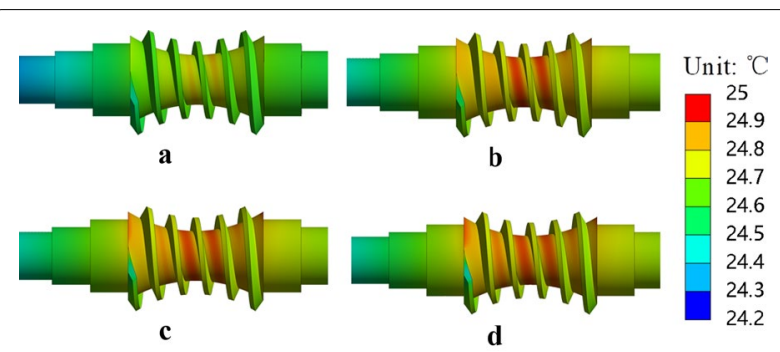

Figure $\mathbf{9}$ Temperature distribution of worm at different rotating speed: a $300 \mathrm{r} / \mathrm{min}$, b $600 \mathrm{r} / \mathrm{min}$, c $900 \mathrm{r} / \mathrm{min}$, d $1200 \mathrm{r} / \mathrm{min}$

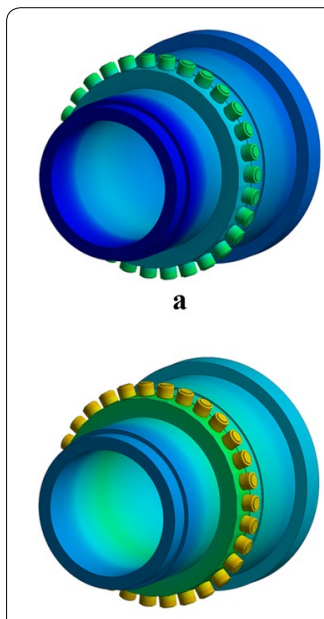

c

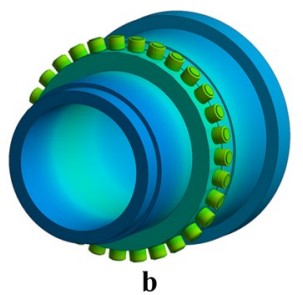

b

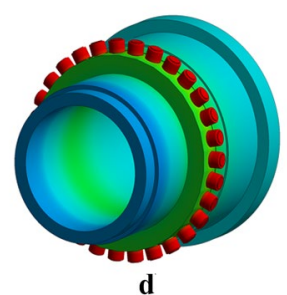

d
Figure 10 Temperature distribution of worm wheel at different rotating speed: a $300 \mathrm{r} / \mathrm{min}$, b $600 \mathrm{r} / \mathrm{min}, \mathbf{c} 900 \mathrm{r} / \mathrm{min}, \mathbf{d} 1200 \mathrm{r} / \mathrm{min}$

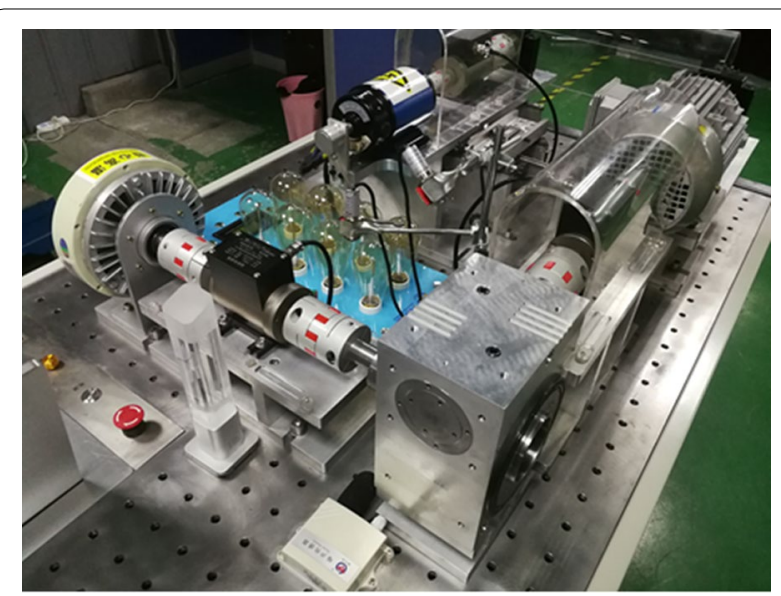

Figure 11 Experimental platform of temperature test

scales for the four groups. The results are shown in Figure 9 and Figure 10.

As can be seen from Figure 9, the highest surface temperature of the worm occurs at the tooth root near the throat, and the temperature of the worm increases with the increase of the rotational speed, but the temperature increases slowly. As can be seen from Figure 10, the highest temperature on the surface of worm gear appears on the surface of the roller, and the temperature of the roller rises obviously with the increase of worm speed.

The increase of temperature will bring thermal deformation, and excessive temperature rise may lead to increased wear and decreased efficiency. As the increase of roller temperature is the most obvious, the thermal deformation caused by roller temperature rise can be taken into account in the design, so as to further improve the transmission performance of the ASEHW gear.

\section{Experimental Verification}

In order to verify the accuracy of simulation, a temperature test platform was built, as shown in Figure 11. A point is selected on the input shaft and output shaft of the gear box respectively, and the infrared temperature sensor is used for temperature test, the test position at the red laser marker as shown in Figure 12.

When the ambient temperature is $22{ }^{\circ} \mathrm{C}$ and the load of worm gear is $50 \mathrm{~N} \cdot \mathrm{m}$, the temperature changes of the ASEHW gear at four rotating speeds of $300 \mathrm{r} / \mathrm{min}, 600 \mathrm{r} /$ $\mathrm{min}, 900 \mathrm{r} / \mathrm{min}$ and $1200 \mathrm{r} / \mathrm{min}$ are tested respectively. In the experiment process, in order to make the measurement as accurate as possible, we first let the ASEHW gear load and run for a period of time at each speed. After the temperature change is relatively stable, the temperature of the ASEHW gear is recorded at each speed continuously for $10 \mathrm{~min}$. 


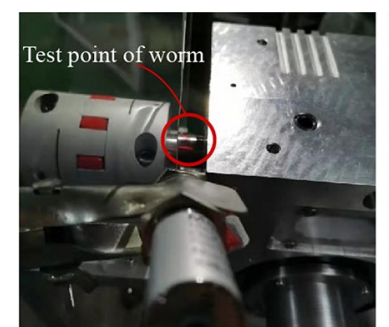

a

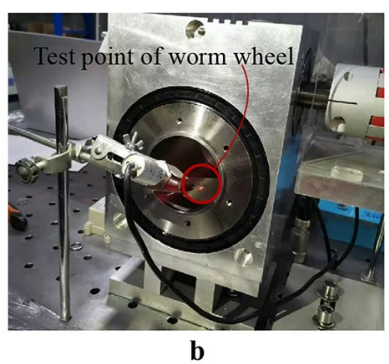

b
Figure 12 a Temperature test point of worm, $\mathbf{b}$ temperature test point of worm wheel

After the experiment is completed, the measured data is plotted as a graph, as shown in Figure 13. When the worm rotation speed is $300 \mathrm{r} / \mathrm{min}$ and $600 \mathrm{r} / \mathrm{min}$, the temperature of worm and worm wheel at the test point is similar. With the increase of worm speed, when the speed reaches $900 \mathrm{r} / \mathrm{min}$, the temperature of worm wheel is higher than the temperature of worm. When the speed reached $1200 \mathrm{r} / \mathrm{min}$, the temperature of worm is much higher than that of worm. The experimental results are consistent with the simulation results, which can prove the correctness of the calculation of thermal power and convection heat transfer coefficient. And

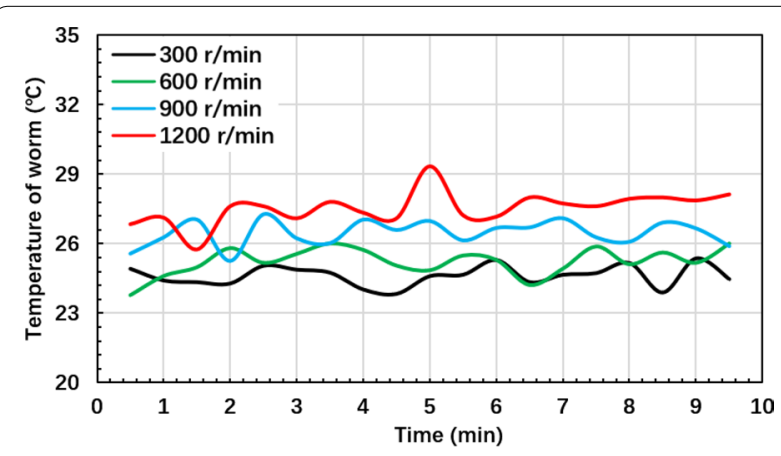

a

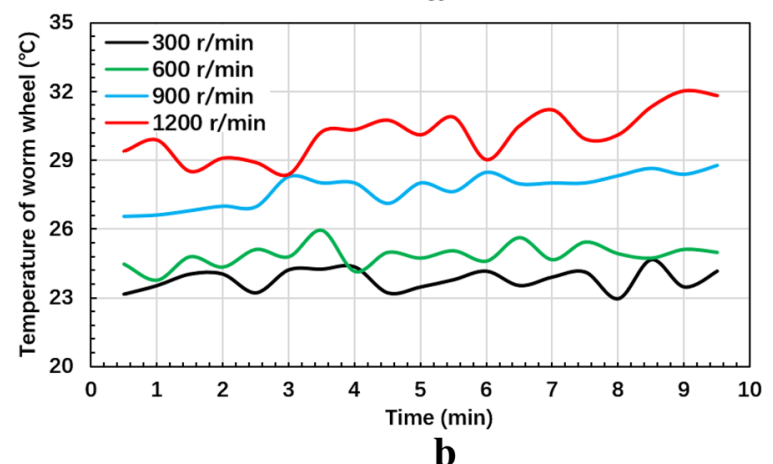

Figure 13 a Temperature variation of worm at different rotating speeds, $\mathbf{b}$ temperature variation of worm wheel at different rotating speeds with the increase of worm speed, the temperature of both the input shaft and the output shaft increases, that is, the thermal power loss increases, which is also consistent with the derived formula.

In order to compare the difference between the simulation and the experimental results, we averaged the temperature measured within $10 \mathrm{~min}$ of the experiment and compared it with the simulation data, as shown in Figure 14. From the comparison results, almost all the simulation temperatures are lower than the experimental temperatures. The reason for this may be that the temperature rise of the bearing is not included in the simulation calculation, but in the actual experiment, because of the heat conduction effect, the temperature rise of the bearing will cause the temperature of the worm wheel and worm to rise further.

It can also be seen from the relative error in Table 4, for the temperature rise at 300, 600 and $900 \mathrm{r} / \mathrm{min}$, the simulation is very close to the experiment, at $1200 \mathrm{r} /$ min, the error between experiment and simulation results is large. This may be due to the higher temperature rise of the bearing at high speeds.

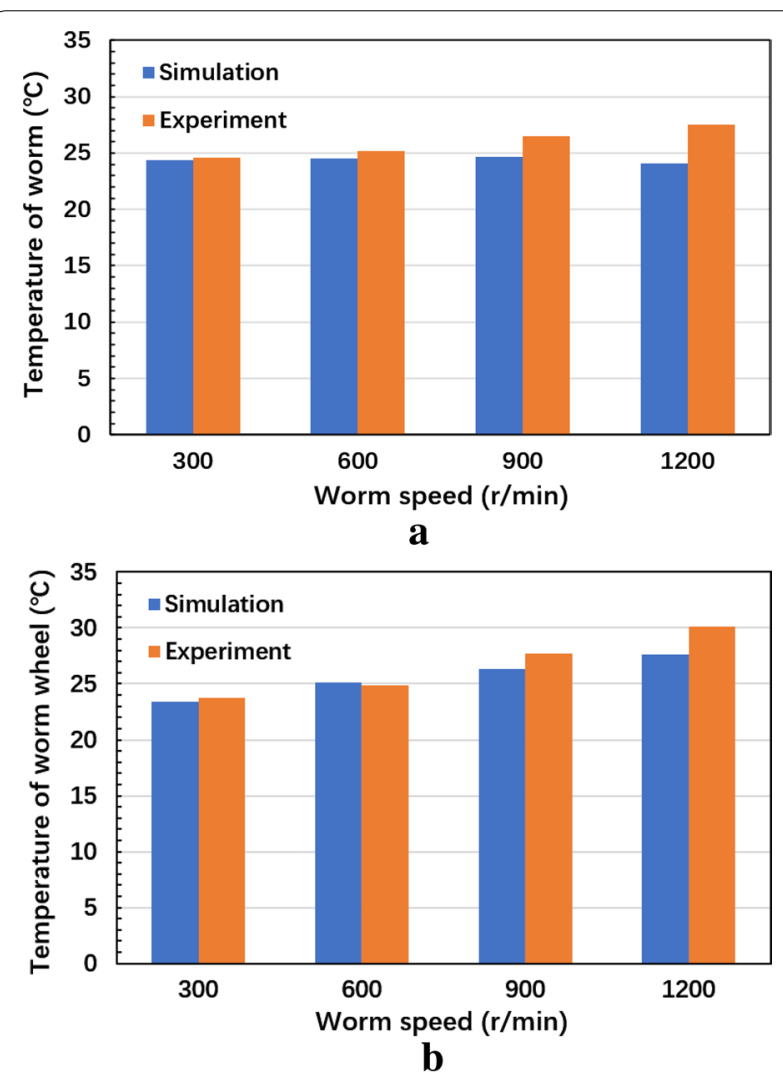

Figure $\mathbf{1 4}$ Comparison of experiment and simulation: a temperature of the worm, $\mathbf{b}$ temperature of the worm wheel 


\begin{tabular}{|c|c|c|c|c|}
\hline & $300 \mathrm{r} / \mathrm{min}$ & $600 \mathrm{r} / \mathrm{min}$ & $900 \mathrm{r} / \mathrm{min}$ & $1200 \mathrm{r} / \mathrm{min}$ \\
\hline Worm & -0.81 & -2.78 & -6.79 & -12.36 \\
\hline Worm wheel & -0.02 & 1.05 & -4.97 & -8.30 \\
\hline
\end{tabular}

Although the relative error between the simulation and the experiment at $1200 \mathrm{r} / \mathrm{min}$ is large, all errors are within the acceptable range. Therefore, it can be considered that the calculation method of the ASEHW gear thermal power proposed in this paper is effective.

\section{Conclusions}

In this paper, through theoretical derivation, simulation analysis and experimental verification, the calculation method of temperature rise of the ASEHW gear is constructed, and the following conclusions are obtained.

(1) In the ASEHW gear, thermal power loss can be divided into two parts: the rolling friction loss of the outer ring of the roller $H_{e}$ and the rotation energy loss of the roller $H_{i}$. And worm speed and load are the main reasons that affect the bulk temperature.

(2) At low speed, the rolling friction loss of the outer ring of the roller $H_{e}$ is close to the rotation energy loss of the roller $H_{i}$. With the increase of worm speed, at high speed, the rotation energy loss of the roller $H_{i}$ will becomes the main factor of thermal power loss.

(3) In the transmission process, the convective heat transfer coefficient of the worm is always higher than worm wheel. And with the increase of worm speed, the convective heat transfer coefficient of worm wheel and worm will increase correspondingly.

(4) In the transmission process, the temperature rise of the roller is the most obvious. On the other hand, the excessively high temperature will lead to the thermal expansion of the roller, resulting in the aggravation of tooth surface wear. Therefore, the thermal deformation of the roller can be taken into account in the design, so as to further improve the performance of ASEHW gear.

\section{Acknowledgements}

Not applicable.

\section{Authors' Contributions}

QXD was in charge of the whole trial; SSW wrote the manuscript; SKW and JW assisted with sampling and laboratory analyses. All authors read and approved the final manuscript.

\section{Authors' Information}

Shisong Wang, born in 1996, is currently a master candidate at School of Mechanical Engineering, Xihua University, China. He received his bachelor degree from Xihua University, China, in 2018. His research interests include new transmission technology.

Shike Wang, born in 1995, is currently a master candidate at school of mechanical engineering, Xihua University, China. He received his bachelor degree from Xihua University, China, in 2017. His research interests include ore crushing simulation.

Jie Wang, born in 1995, is currently a master candidate at school of mechanical engineering, Xihua University, China. He received his bachelor degree from Xihua University, China, in 2017. His research interests include new transmission technology.

Xingqiao Deng, born in 1982, is currently a professor and a PhD candidate supervisor at College of Nuclear Technology and Automation Engineering, Chengdu University of Technology, China. His main research interests include new transmission technology, robot technology, automobile crash simulation.

\section{Funding}

Supported by National Natural Science Foundation of China (Grant No 51875479), and Innovation Fund of Postgraduate of Xihua University, China (Grant No. ycjj2019040).

\section{Competing interests}

The authors declare no competing financial interests.

\section{Author Details}

${ }^{1}$ School of Mechanical Engineering, Xihua University, Chengdu 611730, China ${ }^{2}$ College of Nuclear Technology and Automation Engineering, Chengdu University of Technology, Chengdu 610059, China.

Received: 5 December 2019 Revised: 3 June 2020 Accepted: 28 July 2020 Published online: 28 August 2020

\section{References}

[1] X F Gou, LY Zhu, C J Qi. Nonlinear dynamic model of a gear-rotor-bearing system considering the flash temperature. Journal of Sound and Vibration, 2017, 410: 187-208

[2] $\mathrm{S} \mathrm{Li}, \mathrm{A}$ Anisetti. On the flash temperature of gear contacts under the tribo-dynamic condition. Tribology International, 2016, 97: 6-13.

[3] W Li, J Y Tian. Unsteady-state temperature field and sensitivity analysis of gear transmission. Tribology International, 2017, 116: 229-243.

[4] X G Wang, Y M Wang, Y X Liu, et al. Multi-objective optimization modification of a tooth surface with minimum of flash temperature and vibration acceleration RMS. Journal of Mechanical Science and Technology, 2018, 32(7): 3097-3106.

[5] Y G Liu, JY Peng, B Wang, et al. Bulk temperature prediction of a twospeed automatic transmission for electric vehicles using thermal network method and experimental validation. Proceedings of the Institution of Mechanical Engineers Part D-Journal of Automobile Engineering, 2019, 233(10): 2585-2598

[6] W Li, P F Zhai, L Ding. Analysis of thermal characteristic of spur/helica gear transmission. Journal of Thermal Science and Engineering Applications, 2019, 11(2), https://doi.org/10.1115/1.4041597.

[7] E Letzelter, M Guingand, JP de Vaujany, et al. A new experimental approach for measuring thermal behaviour in the case of nylon $6 / 6$ cylindrical gears. Polymer Testing, 2010, 29(8): 1041-1051.

[8] Z L Xiao, X Shi. Tribological and thermal properties of a crowned gear pair with high-speed and heavy-load in thermal micro-elastohydrodynamic lubrication. Proceedings of the Institution of Mechanical Engineers Part J-Journal of Engineering Tribology, 2020, 234(4): 99-105.

[9] $Y Z$ Wang, W Tang, $Y Y$ Chen, et al. Investigation into the meshing friction heat generation and transient thermal characteristics of spiral bevel gears. Applied Thermal Engineering, 2017, 119: 245-253.

[10] K Mao. A new approach for polymer composite gear design. Wear, 2007, 262(3-4): 432-441. 
[11] K Mao, W Li, C J Hooke, et al. Polymer gear surface thermal wear and its performance prediction. Tribology International, 2010, 43(1-2): 433-439.

[12] J Yi, P D Quinonez. Gear surface temperature monitoring. Proceedings of the Institution of Mechanical Engineers Part J-Journal of Engineering Tribology, 2005, 219(J2): 99-105.

[13] Y Shi, Y P Yao, JY Fei. Analysis of bulk temperature field and flash temperature for locomotive traction gear. Applied Thermal Engineering, 2016, 99: 528-536.

[14] C M C G Fernandes, D M P Rocha, R C Martins, et al. Finite element method model to predict bulk and flash temperatures on polymer gears. Tribology International, 2018, 120: 255-268.

[15] B Luo, W Li. Influence factors on bulk temperature field of gear. Proceedings of the Institution of Mechanical Engineers Part J-Journal of Engineering Tribology, 2017, 231(8): 953-964.

[16] B Cerne, J Duhovnik, J Tavcar. Semi-analytical flash temperature model for thermoplastic polymer spur gears with consideration of linear thermomechanical material characteristics. Journal of Computational Design and Engineering, 2019, 6(4): 617-628.

[17] W Li, P F Zhai, J Y Tian, et al. Thermal analysis of helical gear transmission system considering machining and installation error. International Journal of Mechanical Sciences, 2018, 149: 1-17.

[18] W Li, D Q Pang. Investigation on temperature field of surrounding tooth domain with cracked tooth in gear system. Mechanism and Machine Theory, 2018, 130: 523-538.

[19] G Koffe, F Ville, C Changenet, et al. Investigations on the power losses and thermal effects in gear transmissions. Proceedings of the Institution of Mechanical Engineers Part J-Journal of Engineering Tribology, 2009, 223(J3): 469-479.

[20] H Long, A A Lord, D T Gethin, et al. Operating temperatures of oil-lubricated medium-speed gears: numerical models and experimental results. Proceedings of the Institution of Mechanical Engineers Part G-Journal of Aerospace Engineering, 2003, 217(G2): 87-106.

[21] J H Chang, S J Liu, X Z Hu, et al. Evolution of surface spur gear tooth temperature based on three-dimensional finite element model. Journal of the Brazilian Society of Mechanical Sciences and Engineering, 2019, 41(9), https://doi.org/10.1007/s40430-019-1870-0.

[22] X Q Deng, J Wang, S S Wang, et al. Theory and experiment study of anti-backlash single- and double-roller enveloping hourglass worm gear. Journal of Mechanical Engineering, 2020, 56(3): 88-95. (in Chinese)

[23] X Q Deng, J Wang, S K Wang, et al. Investigation on the backlash of roller enveloping hourglass worm gear: theoretical analysis and experiment. Journal of Mechanical Design, 2019, 141(5), https://doi. org/10.1115/1.4042155.

[24] X Q Deng, S S Wang, Y Hammi, et al. A combined experimental and computational study of lubrication mechanism of high precision reducer adopting a worm gear drive with complicated space surface contact. Tribology International, 2020, 146, https://doi.org/10.1016/j.tribo int.2020.106261.

[25] J T Guo. The mechanism of producing rolling friction force and its calculation. Lubrication Engineering, 1988, (01): 19-24. (in Chinese)

[26] $\mathrm{H}$ Hertz. On the contact of elastic solids. J. Reine AngewMath, 1882, 92: 156-171.

[27] T Jurkschat, M Otto, T Lohner, et al. Determination of the loss behavior and thermal balance of rolling bearings. Forschung Im IngenieurwesenEngineering Research, 2018, 82(2): 149-155.

[28] X Q Deng, W B Zhu, Y H Cheng, et al. Optimal design for an end face engagement worm gear with multiple worm-wheel meshing. Chinese Journal of Mechanical Engineering. 2017, 30(1): 144-151.

[29] X Q Deng, Z P Feng. Theory study of a novel planar enveloping internalmeshing worm drive. Journal of the Brazilian Society of Mechanical Sciences and Engineering, 2017, 39(11): 4807-4818.

[30] X Q Deng, J L Wang, J G Wang, et al. Parametric analysis of the end face engagement worm gear. Chinese Journal of Mechanical Engineering, 2015, 28(6): 1177-1185

\section{Submit your manuscript to a SpringerOpen ${ }^{\odot}$ journal and benefit from:}

- Convenient online submission

- Rigorous peer review

- Open access: articles freely available online

- High visibility within the field

- Retaining the copyright to your article

Submit your next manuscript at $\boldsymbol{\nabla}$ springeropen.com 